\title{
The Status Quo in Health Risk Assessment of Chronic Diseases and Challenges Faced by China
}

\author{
Yalan Zhang, Li Sun and Zongtao Chen* \\ Health Management Centre, Army Medical University, Chongqing, China \\ *Corresponding author: Zongtao Chen, Health Management Centre, Army Medical University, Chongqing, China; E-mail: chenzongtao@126.com
}

Received: March 23, 2021; Accepted: March 30, 2021; Published: March 31, 2021

\begin{abstract}
Keywords: Challenges, Chronic diseases, Health risk assessment

\section{Introduction}

The mortality due to chronic diseases accounted for about $70 \%$ of the total deaths [1-3]. In 2012, deaths from chronic diseases accounted for $86.6 \%$ of the total deaths in China, higher than the global average over the same period [4]. Due to the slow onset and long incubation of the chronic disease, prevention and early intervention, which screen high-risk patients by studying the health risk factors, are recognized as effective ways to reduce the incidence. Health risk assessment, which aims to study the relationship of the risk factors with incidence and case fatality rate as well as the inherent laws, is a basic technology and the core for screening the patients with chronic disease.
\end{abstract}

As a key technology for chronic disease management, risk assessment plays an important role in chronic disease prevention and control. This paper aims to summarize the status quo in risk assessment of chronic disease in recent years in hope of providing guidance for chronic disease assessment in China.

\section{The Status Quo in Chronic Disease Risk Assessment at Home and Abroad}

In 1967, the National Institutes of Health of the United States established the Framingham risk model [5]. Risk factors for cardiovascular disease (CVD), including age, systolic blood pressure etc., were included in the model to predict the risk of coronary heart disease in the next 10 years of individual patients. Framingham model is a milestone in the history of chronic disease risk assessment, promoting the innovation of risk assessment technology. After a series of improvements [6-8], the prediction ability of the model has been further improved. Other common CVD assessment models include the National Cholesterol Education Program Adult Treatment Panel III (NCEP-ATP III) [9]; QRISK risk score [10]; Reynolds Risk Score [11]; ischemic cardiovascular disease (ICVD) risk assessment in China [12]; and Chinese CMCS model [8].

Based on 2 large cohort studies, the Harvard Cancer Risk Index Working Group developed a risk assessment tool for cancers, which can be used to assess the risk of cancer in the population aged over 40 [13]. This method is simple, fast and widely accepted. In addition, Gail Model [14], as a comparatively accurate breast cancer assessment model, can assess the risk of breast cancer within 5 years or throughout the life of an individual patient, and is widely used in clinical practice [15]. In 2018, based on Framingham model, Southwest Hospital in Chongqing, China, developed a risk assessment model for asymptomatic cancer which integrates cancer statistics in 2015 and 2018 in China, and the data on chronic disease risk assessment and standardization project of preventive medicine. Currently the model is in clinical trial.

Over the past 50 years, remarkable progress has been made in the prevention of chronic disease by risk assessment: the mortality rate of chronic disease has been significantly reduced in many countries worldwide [16]. Since the 1980s, China has gradually built ICVD risk assessment and CMCS model [8,12], a lifetime risk assessment model for cardiovascular disease and stroke $[17,18]$ and China-PAR model [19-21], which conformed with the national situation. However, most of the existing risk assessment models in China lack external validation, and thus the application of the models is limited [22]. As for early screening for cancer, many expert consensuses have been reached [23-25], but the risk assessment model based on multiple risk factors is still in the pilot stage.

\section{The Challenges with Health Risk Assessment in China}

1. There is a lack of high-quality data. Large cohort studies are an important source of high-quality data; At present, there are China kadoorie biobank (CKB) and prospective follow-up studies on factors impacting development of cardiovascular disease and its mortality, but they are still in early phase.

2. The standards for health data have not been unified. Basic data for health risk assessment may come from diversified sources, such as smart watches and wearable devices etc. However, the standards of health management data have not been developed to meet the real needs in China.

3. The modeling method is not innovative enough. The main risk factors included were lifestyle-related and metabolic 
risk factors [26], such as smoking and BMI, while other factors, including the time sequence of chronic diseases [27], characteristics of disease evolution in population [28], environmental factors and social determinants, have not been considered [29]. In addition, support vector machine [22], classification and regression tree etc. are less frequently used.

4. Promotion is limited. There is a lack of a sound health education system for chronic diseases, the public have limited knowledge about chronic diseases, their attitude towards chronic disease risk assessment is ambiguous, and the compliance is not high.

\section{Competing Interests Statement}

The authors declare that they have no conflicts of interest.

\section{References}

1. WHO (2020) Disease burden and mortality estimates: cause-specific mortality, 2000-2016. https://www.who.int/healthinfo/global_burden_disease/estimates/en/

2. WHO (2018) World health statistics 2018: monitoring health for the SDGs. Geneva: World Health Organization.

3. NCD Countdown 2030 collaborators (2018) NCD Countdown 2030: worldwide trends in non-communicable disease mortality and progress towards Sustainable Development Goal target 3.4. Lancet 392: 1072-1088.

4. Zhu XL, Luo JS, Zhang XC, Zhai Y, Wu J (2017) China's efforts on management, surveillance, and research of noncommunicable diseases: NCD Scorecard Project. Ann Glob Health 83: 489-500. [crossref]

5. Truett J, Cornfield J, Kannel W (1967) A multivariate analysis of the risk of coronary heart disease in Framingham. J Chronic Dis 20: 511-524. [crossref]

6. Kannel WB, Mc Gee D, Gordon T (1976) A general cardiovascular risk profile: the Framingham Study. Am J Cardiol 38: 46-51. [crossref]

7. Wilson PW, D'Agostino RB, Levy D, Belanger AM, Silbershatz H, et al. (1998) Prediction of coronary heart disease using risk factor categories. Circulation 97: 1837-1847. [crossref]

8. Liu J, Hong Y, DAgostino RB, Wu Zh, Wang W, et al. (2004) Predictive value for the Chinese population of the Framingham CHD risk assessment tool compared with the Chinese Multi-Provincial Cohort Study. JAMA 291: 2591-2599. [crossref]

9. National Cholesterol Education Program Expert on Detection, Evaluation, and Treatment of High Blood Cholesterol in Adults (2001) Executive summary of the third report of the National Cholesterol Education Program (NCEP) Expert Panel on Detection, Evaluation, and Treatment of High Blood Cholesterol in Adults(Adults Treatment Panel III). JAMA 285: 2486-2497. [crossref]

10. Hippisley CJ, Coupland C, VinogradovaY Robson J, Margaret M, Brindle P (2007) Derivation and validation of QRISK, a new cardiovascular disease risk score for the United Kingdom: Prospective open cohort study. BMJ 7611:136-141. [crossref]

11. Ridker PM, Buring JE, Rifai N, Nancy RC (2007) Development and validation of improved algorithms for the assessment of global cardiovascular risk in women: The Reynolds Risk Score. JAMA 297: 611-619. [crossref]
12. Wu YF, Liu XQ, Li X, Li Y, Zhao LC, et al. (2006) Estimation of 10-year risk of fatal and nonfatal ischemic cardiovascular diseases in Chinese adults. Circulation 114: 2217-2225. [crossref]

13. Kim DJ, Rockhill B, Colditz GA (2004) Validation of the Harvard cancer risk index a prediction tool for individual cancer risk. J Clin Epidemiol 57: 332-340. [crossref]

14. Li X, Yang XX, Li M (2011) Research progress and clinical application of breast cancer risk assessment model Cancer Research on Prevention and Treatment 5: 604-606.

15. He DD, Wu F, Wen XS, Tang H, Fang H (2016) Progress in Gail models for breast cancer risk assessment. Tumor 36: 1389-1394.

16. NCD Countdown 2030 collaborators (2020) NCD Countdown 2030: pathways to achieving Sustainable DevelopmentGoal target 3.4. Lancet 26: 396: 918-934. [crossref]

17. Wang Y, Liu J, Wang W, Wang M, Qi Y, et al. (2015) Lifetime risk for cardiovascular disease in a Chinese population: the Chinese Multi-Provincial Cohort Study. Eur J PrevCardiol 22: 380-388. [crossref]

18. Wang Y, Liu J, Wang W, Wang M, Yue Qi, et al. (2016) Lifetime risk of stroke in young-aged and middle-aged Chinese population: the Chinese Multi-Provincial Cohort Study[J]. J Hypertens 34: 2434-2440. [crossref]

19. Yang X, Li J, Hu D, Chen JC, Li Y, et al. (2016) Predicting the 10-year risks of atherosclerotic cardiovascular disease in Chinese population: the China-PARproject (prediction for ASCVD risk in China). Circulation 134: 1430-1440. [crossref]

20. Yang XL, Chen JC, Li JX, Cao J, Lu XF, et al. (2016) Risk stratification of atherosclerotic cardiovascular disease in Chinese adults[J]. Chronic Dis Transl Med 2: 102-109. [crossref]

21. Liu F, Li J, Chen J, Hu DH, Li Y, et al. (2018) Predicting lifetime risk for developing atherosclerotic cardiovascular disease in Chinese population: the China-PAR project. Sci Bull 63: 779-787.

22. Li ZY, Shi TX, Huang XX, Shi JW, Huang JL, et al. (2020) Research status of chronic disease risk assessment at home and abroad and analysis of breakthrough in China. Chinese Health Resources 23: 49-54.

23. Zhuan Liao, Tao Sun, Hao Wu, Yang F, Zou W B (2014) Consensus on screening and endoscopic diagnosis and treatment of early gastric cancer in China. Chinese Journal of Gastroenterology 7: 408-427.

24. Li P, Wang YJ, Chen GY, Xu CQ (2015) Consensus on screening, diagnosis and treatment of early colorectal cancer and precancerous lesions in China. Chinese Journal of Practical Internal Medicine 3: 211-227.

25. National Digestive Endoscopy Improvement Systems (2019) Expert consensus on screening of early esophageal cancer and precancerous lesions in China. Chinese Journal of Digestive Endoscopy 11: 793-801. [crossref]

26. World Health Organization (2010) Global Status Report on Non-Communicable Diseases. Geneva.

27. Liu R, Shi JW, Yu DH, Zhuang SQ, Dong ZB, et al. (2017) Bottleneck of chronic disease trend prediction and construction of optimization model [J]. Chinese Journal of Public Health 33: 1552-1555.

28. Damen JA, Hooft L, Schuit E, Debray T, Collins G, et al. (2016) Prediction models for cardiovascular disease risk in the general population: systematic review[J]. BMJ 353: i2416. [crossref]

29. AdjayeGK, Vaughan M (2019) Reframing NCDs? An analysis of current debates. Glob Health Action 12: 1-11. [crossref]

\section{Citation:}

Zhang Y, Sun L, Chen Z (2021) The Status Quo in Health Risk Assessment of Chronic Diseases and Challenges Faced by China. Internal Med Res Open J Volume 6(2): 1-2. 